\title{
SELETIVIDADE DO HERBICIDA SAFLUFENACIL APLICADO EM PÓS-EMERGÊNCIA EM DEZ VARIEDADES DE CANA-DE-AÇÚCAR NA CONDIÇÃO DE SOCA
}

\author{
S.Í.A. Costa ${ }^{1}$, D. Martins ${ }^{1}$, L.A. Cardoso ${ }^{1}$, A.C.P. Rodrigues ${ }^{2}$, H.S. Vitorino ${ }^{1}$, R.P. Marques ${ }^{1}$
}

${ }^{1}$ Universidade Estadual Paulista, Faculdade de Ciências Agronômicas, Departamento de Produção e Melhoramento Vegetal, Rua Dr. José Barbosa de Barros, 1780, CEP 18610-307, Botucatu, SP, Brasil. E-mail: sauloalmeida@fca.unesp.br

\section{RESUMO}

Este trabalho teve como objetivo avaliar a seletividade do herbicida saflufenacil de forma isolada e em mistura, aplicado em pós-emergência inicial sobre dez variedades de cana-de-açúcar em condição de cana-soca. O experimento foi instalado no Município de Botucatu, SP. O delineamento experimental utilizado foi o de blocos casualizados com os tratamentos dispostos em parcelas subdivididas tendo como tratamento principal as variedades de cana-de-açúcar e como tratamento secundário o herbicida saflufenacil + Assist $\left(0,07 \mathrm{~kg} \mathrm{ha}^{-1}+0,5 \% \mathrm{v} / \mathrm{v}\right)$; saflufenacil + Break Thru $\left(0,140 \mathrm{~kg} \mathrm{ha}^{-1}+0,05 \% \mathrm{v} / \mathrm{v}\right)$; saflufenacil $\left(0,280 \mathrm{~kg} \mathrm{ha}^{-1}\right)$ e ametryne + clomazone $(3,0+2,0$ Li. a. ha-1), aplicados aos 49 dias após o corte, além de uma testemunha sem aplicação. As plantas de cana-de-açúcar encontravam-se, por ocasião da aplicação, com 2 a 4 folhas. As dez variedades utilizadas foram: SP83-2847, SP80-3280, RB855453, SP80-1842, SP89-1115, RB867515, PO8862, RB855156, SP80-1816 e SP81-3250. Para a aplicação dos herbicidas utilizou-se um pulverizador costal pressurizado a $\mathrm{CO}_{2}$ equipado com barra de aplicação com seis pontas Teejet XR11002VS, à $200 \mathrm{kPa}$ no volume de aplicação de $200 \mathrm{~L} \mathrm{ha}^{-1}$. As avaliações visuais de controle foram realizadas aos 3, 7, 15, 21, 30, 45 e 60 dias após a aplicação. As injúrias visuais inicialmente observadas nas plantas de cana-de-açúcar foram dependentes da variedade e dos herbicidas e doses testados. Todos os tratamentos químicos foram seletivos às diferentes variedades estudadas, não afetando o rendimento de colmos e açúcar.

PALAVRAS-CHAVE: Cana-de-açúcar, seletividade, herbicidas.

\section{ABSTRACT}

\begin{abstract}
SELECTIVITYOFTHEHERBICIDESAFLUFENACILAPPLIEDINPOST-EMERGENCEONTEN VARIETIES OF SUGARCANE (SACCHARUM SPP.) IN THE SECOND YEAR AFTER PLANTING. This study was aimed to evaluate the selectivity of the herbicide saflufenacil applied alone and mixed, in post-emergence on 10 sugarcane cultivars in the second year after planting. The experiment was carried out in Botucatu, state of São Paulo, Brazil. The experimental design was a randomized split plot with 4 replications, with the cultivars set up in the plot and the herbicides in the subplot. The treatments were: saflufenacil + Assist $\left(0.07 \mathrm{~kg} \mathrm{ha}^{-1}+0.5 \mathrm{v} / \mathrm{v}\right)$; saflufenacil + Break Thru $\left(0.140 \mathrm{~kg} \mathrm{ha}^{-1}+0.05 \% \mathrm{v} / \mathrm{v}\right)$; saflufenacil $\left(0.280 \mathrm{~kg} \mathrm{ha}^{-1}\right)$ and ametryne + clomazone $\left(2.0+3.0 \mathrm{~L} \mathrm{ha}^{-1}\right)$ applied at 49 days after first harvest, and a control without application. The plants had from 2 to 4 leaves at the application time. The cultivars were: SP83-2847, SP80-3280, RB855453, SP80-1842, SP89-1115, RB867515, PO-8862, RB855156, SP80-1816 and SP81-3250. The herbicide was applied using Teejet XR11002VS spray equipment with six spray nozzles, at $200 \mathrm{kPa}$ and, $200 \mathrm{~L} \mathrm{ha}^{-1}$ spray volume. Visual evaluations were made at 3, 7, 15, 21, 30,45 and 60 days after application. The initial visual injuries observed in the sugarcane plants were dependent on cultivars, the herbicides and, doses tested. All chemical treatments tested were selective to the different cultivars studied, without affecting the crop and sugar production.
\end{abstract}

KEY WORDS: Sugarcane, selectivity, herbicides.

A cultura da cana-de-açúcar, como todas as outras, apresenta durante seu desenvolvimento concorrência com as plantas chamadas daninhas. Tal fato ocorre por estas plantas possuírem mecanismos mais desenvolvidos para o aproveitamento dos recursos necessários ao seu desenvolvimento, taiscomo: nutrientes, água, luze podem ocasionar redução na produção canavieira que podealcançar 85\% (VICTÓRIAFILHO; CHRISTOFFOLETI, 2004).

O principal método de controle das plantas daninhas na cultura da cana-de-açúcar é o químico,

${ }^{2}$ Universidade Estadual do Oeste do Paraná, Marechal Cândido Rondon, PR, Brasil. 
através da aplicação de herbicidas, tanto na condição de pré como de pós-emergência. O controle químico de plantas daninhas em áreas de cana-de-açúcar é uma prática bastante difundida em todo o país. A lavoura ocupa um grande espaço no consumo de herbicidas, tanto em volume como em área.

Uma grande dificuldade nesse tipo de manejo na cultura canavieira é a necessidade de herbicidas com ação sistêmica em pós-emergência e seletivos a cultura. O contínuo desenvolvimento de novos herbicidas para uso nesta cultura, bem como a dinâmica de introdução ou troca de variedades, faz com que o estudo da interação destes dois fatores torne-se constante (TERRA, 2003).

A seletividade de novos herbicidas deve ser avaliada nas variedades de cana-de-açúcar mais plantadas, assim como a tolerância de variedades recém lançadas aos herbicidas tradicionalmente utilizados nesta cultura também deve ser investigada. Na prática, estas avaliações são realizadas em estudos específicos sobre seletividade, com metodologia própria para cana-de-açúcar e sempre sem a presença da comunidade infestante FAGLIARI et al. (2001).

A ausência de injúrias visuais nas plantas tratadas com um determinado herbicida também não é suficiente para determinar a sua tolerância a este produto, sendo necessária para tal uma avaliação mais detalhada na quantidade e qualidade do seu produto final. Especificamente, para a cana-deaçúcar, os parâmetros produtivos normalmente avaliados são o comprimento, número e peso de colmos, enquanto que a qualidade pode ser analisada mensurando os teores de pol, brix e fibra, além de quantificar a produção de açúcar.

O herbicida saflufenacilé uma nova molécula em desenvolvimento, usado em associação com DASH $\mathrm{HC}$ e outros adjuvantes, e encontra-se em fase de registro para diversas culturas no Brasil, incluindo a cana-de-açúcar (OsIPE et al., 2009) O objetivo deste estudo foi avaliar a seletividade do herbicida saflufenacil em diferentes variedades de cana-de-açúcar, em condição de cana-soca.

Otipo de solo daárea experimental foi classificado como Nitossolo Vermelho Estruturado (EMBRAPA, 1999), sendo analisado química e fisicamente na profundidade de até $0,20 \mathrm{~m}$, pelo laboratório de solos da FCA/UNESP, para sua caracterização. Os resultados das análises encontram-se demonstrados na Tabelas 1.

Para a adubação da cana soca foi utilizada a fórmula 20-05-20, aplicando-se $600 \mathrm{~kg}$. ha-1. $\mathrm{O}$ es- paçamento da cultura utilizado foi de $1,40 \mathrm{~m}$ entre linhas de plantio.

Realizou-se o plantio e a colheita de dez variedades de cana-de-açúcar, cana-de-ano-e-meio, em 8/2/2007 e 30/7/2008, respectivamente. A colheita da cana soca foi realizada em 24/7/2009.

As variedades utilizadas foram: SP83-2847, SP803280, SP80-1816, SP80-1842, SP89-1115 e SP81-3250 que juntas representam área plantada de 775.225 mil hectares no Estado de São Paulo, as variedades RB855453, RB867515 e RB855156 somam 861.444 mil hectares a PO-8862 que possui uma área de 33.279 mil hectares nos canaviais paulistas (CHAPOLAetal., 2011).

Independente da aplicação dos herbicidas, o experimento foi mantido no "limpo" durante toda condução do experimento através de capinas manuais.

A aplicação dos herbicidas foi realizada em 17/9/2008 aos 49 DAC (dias após a colheita) e, no momento da aplicação, as plantas apresentavam de 2 a 4 folhas. As condições meteorológicas no momento das aplicações foram: temperatura do ar de $27^{\circ} \mathrm{C}$, umidade relativa do ar de $65 \%$ e velocidade de vento de 2 a $4 \mathrm{~km} \mathrm{~h}^{-1}$, medida a $1 \mathrm{~m}$ de altura da superfície do solo. O equipamento utilizado na aplicação dos tratamentos foi um pulverizador costal, pressurizado a $\mathrm{CO}_{2}$ e equipado com barra de aplicação contendo seis pontas Teejet XR11002VS, a $200 \mathrm{KPa}$ de pressão e $200 \mathrm{~L} \mathrm{ha}^{-1}$.

O delineamento experimental utilizado foi o de blocos casualizados com os tratamentos dispostos em parcelas subdivididas tendo como tratamento principal as variedades de cana-de-açúcar e como tratamento secundário os herbicidas. Cada parcela foi constituída de 5 subparcelas, sendo cada uma composta de $6 \mathrm{~m}$ de comprimento por 5,6 $\mathrm{m}$ de largura $\left(33,6 \mathrm{~m}^{2} /\right.$ parcela $)$.

As avaliações visuais de fitotoxicidade foram realizadas aos 3, 7, 15, 21, 30, 45 e 60 dias após a aplicação (DAA) dos herbicidas, por meio de uma escala percentual de notas, na qual "zero" correspondeu a nenhuma injúria e "cem" a morte das plantas (SBCPD, 1995).

Uma semana antes da colheita, foram retiradas amostras de 10 colmos por parcela. Todos os colmos foram submetidos aos despontes na altura da gema apical (ponto de quebra), encaminhando-os para o "Laboratório de Pureza de Cana" da Unidade de Produção do Grupo COSAN - Unidade Barra, para serem processados e determinados o teor de Pol, Brix e fibra, conforme CONSECANA (2006).

Tabela 1 - Caracterização química e física do solo da área experimental Botucatu, SP, 2008/2009.

\begin{tabular}{|c|c|c|c|c|c|c|c|c|c|c|c|c|c|}
\hline $\mathrm{pH}$ & M.O. & $\mathrm{P}_{\text {resina }}$ & $\mathrm{Al}^{3+}$ & $\mathrm{H}+\mathrm{Al}$ & K & $\mathrm{Ca}$ & $\mathrm{Mg}$ & SB & $\mathrm{CTC}$ & \multirow[t]{2}{*}{$\mathrm{V} \%$} & Argila & Silte & Argila \\
\hline $\mathrm{CaCl}_{2}$ & $\mathrm{~g} / \mathrm{dm}^{3}$ & $\mathrm{mg} / \mathrm{dm}^{3}$ & \multicolumn{7}{|c|}{ 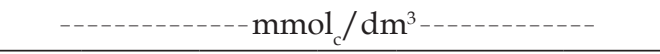 } & & \multicolumn{3}{|c|}{ 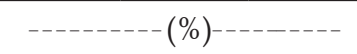 } \\
\hline 5,3 & 12 & 10 & 0 & 22 & 0,7 & 22 & 5 & 28 & 50 & 56 & 57 & 18 & 25 \\
\hline
\end{tabular}


Os colmos de cada parcela foram colhidos no dia $24 / 7 / 2009$, pelo método manual, sem queima. Para o cálculo da produtividade agrícola foi realizada a pesagem dos colmos equivalentes a $2 \mathrm{~m}$ de cada parcela, extrapolando-os para a obtenção da produtividade em toneladas por hectare $\left(\mathrm{t} \mathrm{ha}^{-1}\right)$. Para tal, utilizou-se uma balança com capacidade para mil quilos. Os resultados obtidos foram submetidos à analise de variância pelo teste $\mathrm{F}$, as médias dos tratamentos comparadas pelo teste de Tukey a 5\% de probabilidade.

Na Tabela 2 estão apresentadas as porcentagens de fitointoxicação visual para todas as variedades de cana-de-açúcar avaliadas em diversos períodos de tempo após a aplicação dos diferentes herbicidas em pós-emergência inicial da cultura.

Tabela 2 - Valores médios da porcentagem de fitotointoxicação em dez variedades de cana-de-açúcar após a aplicação de diferentes caldas herbicidas. Botucatu, SP, 2008.

\begin{tabular}{|c|c|c|c|c|c|c|c|c|c|}
\hline \multirow{2}{*}{ Variedades } & \multirow{2}{*}{ Herbicidas } & \multirow{2}{*}{$\begin{array}{l}\text { Dose } \\
\left(\text { kg i.a. ha }{ }^{-1}\right)\end{array}$} & \multicolumn{7}{|c|}{ Dias após a aplicação } \\
\hline & & & 3 & 7 & 15 & 21 & 30 & 45 & 60 \\
\hline \multirow{4}{*}{ 1. SP83-2847 } & aflufenacil + Assist & \multirow{4}{*}{$\begin{array}{l}0,070+0,5 \% \mathrm{v} / \mathrm{v} \\
0,140+0,05 \% \\
\mathrm{v} / \mathrm{v} \\
0,280 \\
1,5+1,0\end{array}$} & 44,25 & 40,50 & 33,75 & 11,75 & 6,25 & 2,75 & 0,00 \\
\hline & saflufenacil+ Break Thru & & 18,25 & 21,50 & 18,00 & 8,00 & 4,25 & 1,25 & 0,00 \\
\hline & saflufenacil & & 8,25 & 17,50 & 19,25 & 7,25 & 3,75 & 1,75 & 0,00 \\
\hline & + clomazone & & 12,75 & 15,50 & 31,00 & 21,75 & 13,50 & 4,25 & 0,50 \\
\hline \multirow{4}{*}{ 2. SP80-3280 } & saflufenacil + Assist & \multirow{3}{*}{$\begin{array}{l}0,070+0,5 \% \mathrm{v} / \mathrm{v} \\
0,140+0,05 \% \\
\mathrm{v} / \mathrm{v} \\
0,280\end{array}$} & 34,25 & 37,50 & 32,50 & 12,50 & 4,50 & 3,00 & 0,00 \\
\hline & saflufenacil+ Break Thru & & 10,25 & 14,00 & 14,25 & 4,50 & 2,75 & 1,25 & 0,00 \\
\hline & saflufenacil & & 5,50 & 13,75 & 13,75 & 5,25 & 3,00 & 1,25 & 0,00 \\
\hline & one & $1,5+1,0$ & 6,25 & 12,25 & 22,50 & 15,00 & 7,25 & 4,00 & 0,00 \\
\hline \multirow{4}{*}{ 3. RB855453 } & saflufe & \multirow{4}{*}{$\begin{array}{l}0,070+0,5 \% \mathrm{v} / \mathrm{v} \\
0,140+0,05 \% \\
\mathrm{v} / \mathrm{v} \\
0,280 \\
1,5+1,0\end{array}$} & 30,50 & 33,25 & 22,25 & 10,25 & 5,25 & 1,75 & 0,00 \\
\hline & saflufenacil+ Break Thru & & 14,25 & 18,00 & 13,50 & 6,25 & 3,75 & 1,75 & 0,00 \\
\hline & saflufe & & 2,75 & 9,50 & 10,50 & 4,50 & 2,50 & 1,25 & 0,00 \\
\hline & clomazone & & 7,00 & 14,25 & 22,50 & 12,75 & 6,25 & 3,50 & 0,00 \\
\hline \multirow{4}{*}{ 4. SP80-1842 } & saflufenacil + Assist & \multirow{4}{*}{$\begin{array}{l}0,070+0,5 \% \mathrm{v} / \mathrm{v} \\
0,140+0,05 \% \\
\mathrm{v} / \mathrm{v} \\
0,280\end{array}$} & 61,25 & 54,50 & 36,25 & 13,75 & 7,25 & 2,00 & 0,00 \\
\hline & saflufenacil+ Break Thru & & 24,25 & 24,25 & 18,75 & 9,25 & 3,75 & 1,25 & 0,00 \\
\hline & saflufenacil & & 12,25 & 21,50 & 18,25 & 8,00 & 3,75 & 1,25 & 0,00 \\
\hline & ne & & 7,00 & 15,00 & 21,25 & 11,75 & 5,25 & 2,75 & 0,00 \\
\hline \multirow{4}{*}{ 5. SP89-1115 } & il + Assist & \multirow{4}{*}{$\begin{array}{l}0,070+0,5 \% \mathrm{v} / \mathrm{v} \\
0,140+0,05 \% \\
\mathrm{v} / \mathrm{v} \\
0,280 \\
1,5+1,0\end{array}$} & 29,50 & 33,75 & 31,25 & 11,75 & 6,00 & 2,50 & 0,00 \\
\hline & saflufenacil+ Break Thru & & 20,00 & 20,75 & 17,00 & 7,00 & 3,75 & 1,75 & 0,0 \\
\hline & Sc & & 4,50 & 13,75 & 14,25 & 8,25 & 3,25 & 1,75 & 0,00 \\
\hline & ne & & 4,50 & 14,75 & 25,75 & 17,25 & 9,50 & 3,75 & 0,00 \\
\hline \multirow{4}{*}{ 6. RB867515 } & cil + Assist & \multirow{4}{*}{$\begin{array}{l}0,070+0,5 \% \mathrm{v} / \mathrm{v} \\
0,140+0,05 \% \\
\mathrm{v} / \mathrm{v} \\
0,280 \\
1,5+1,0\end{array}$} & 43,75 & 41,25 & 36,25 & 16,75 & 8,00 & 3,25 & 0,00 \\
\hline & lacil+ Break Thru & & 14,25 & 18,25 & 18,75 & 8,25 & 4,50 & 2,00 & 0,00 \\
\hline & caflu & & 6,50 & 12,50 & 13,50 & 6,75 & 2,75 & 1,75 & 0,00 \\
\hline & clom & & 5,25 & 15,00 & 29,25 & 11,75 & 5,75 & 3,50 & 0,00 \\
\hline \multirow{4}{*}{ 7. PO-8862 } & saflufenacil + Assist & \multirow{3}{*}{$\begin{array}{l}0,070+0,5 \% \mathrm{v} / \mathrm{v} \\
0,140+0,05 \% \\
\mathrm{v} / \mathrm{v} \\
0,280\end{array}$} & 72,00 & 46,75 & 33,75 & 15,00 & 5,25 & 2,00 & 0,00 \\
\hline & 1+ Break Thru & & 30,00 & 28,75 & 23,00 & 11,50 & 3,75 & 1,00 & 0,00 \\
\hline & & & 15,00 & 26,00 & 20,00 & 8,75 & 4,25 & 1,50 & 0,00 \\
\hline & & $1,5+1,0$ & 7,25 & 15,00 & 35,00 & 20,00 & 15,25 & 3,50 & 0,00 \\
\hline \multirow{4}{*}{ 8. RB855156 } & cil + Assist & \multirow{4}{*}{$\begin{array}{l}0,070+0,5 \% \mathrm{v} / \mathrm{v} \\
0,140+0,05 \% \\
\mathrm{v} / \mathrm{v} \\
0,280 \\
1,5+1,0\end{array}$} & 31,75 & 33,25 & 27,50 & 10,00 & 3,25 & 1,75 & 0,00 \\
\hline & saflufenacil+ Break Thru & & 7,50 & 10,75 & 10,00 & 4,00 & 1,50 & 1,00 & 0,00 \\
\hline & saflufenacil & & 2,25 & 8,75 & 9,50 & 4,00 & 1,50 & 1,00 & 0,00 \\
\hline & ametryne + clomazone & & 6,25 & 13,75 & 24,25 & 20,75 & 10,50 & 3,75 & 0,00 \\
\hline \multirow{4}{*}{ 9. SP80-1816 } & saflufenacil + Assist & \multirow{4}{*}{$\begin{array}{l}0,070+0,5 \% \mathrm{v} / \mathrm{v} \\
0,140+0,05 \% \\
\mathrm{v} / \mathrm{v} \\
0,280 \\
1,5+1,0\end{array}$} & 53,75 & 42,50 & 38,75 & 15,50 & 7,25 & 3,00 & 0,00 \\
\hline & + Break Thru & & 17,00 & 19,50 & 20,00 & 7,00 & 4,25 & 1,75 & 0,00 \\
\hline & saflufenacil & & 10,25 & 18,25 & 20,50 & 6,75 & 4,00 & 1,50 & 0,00 \\
\hline & ametryne + clomazone & & 7,25 & 15,00 & 31,25 & 17,00 & 11,50 & 4,25 & 0,25 \\
\hline \multirow{4}{*}{ 10. SP81-3250 } & saflufenacil + Assist & & 46,25 & 38,75 & 32,50 & 15,25 & 6,50 & 2,25 & 0,00 \\
\hline & saflufenacil+ Break Thru & $+0,05 \%$ & 10,50 & 11,75 & 14,25 & 6,00 & 2,75 & 1,75 & 0,00 \\
\hline & & 0,280 & 4,00 & 13,00 & 13,50 & 5,25 & 2,75 & 1,50 & 0,00 \\
\hline & omazone & $1,5+1,0$ & 6,25 & 15,00 & 31,25 & 20,50 & 14,25 & 5,25 & 1,00 \\
\hline
\end{tabular}


Pode-se observar que, aos 3 DAA, os herbicidas utilizados no estudo proporcionaram visualmente a todas as variedades de cana-de-açúcar injúrias na parte aérea das plantas. Os sintomas mais severos de injúrias foram verificados nas parcelas tratadas com o herbicida saflufenacile, principalmente, com a mistura de saflufenacil + óleo mineral Assist seguida da mistura de saflufenacil + surfatante Break Thru, no qual em algumas variedades, como: PO-8862, SP80-1816 e SP80-1842 os níveis de injúrias foram consideravelmente elevados, ultrapassando $50 \%$. Ressalta-se que o tratamento isolado com saflufenacil, mesmo sendo na maior dose, apresentou níveis bem baixos de injúrias para a maioria das variedades. A maior dose de saflufenacil $(0,280 \mathrm{~g}$ $\mathrm{ha}^{-1}$ ) proporcionou injúrias intermediárias, uma vez que os níveis de sintomas sempre estiveram entre 2 e $15 \%$. Ainda, notou-se que, independente da dose de saflufenacil, a mistura com Assist ou Break Thru elevou as injúrias nas folhas das plantas de cana, seguidos do tratamento padrão utilizado (ametryne + clomazone), no qual os efeitos fitotóxicos variaram de 4,5 a 12,7\%, dependendo da variedade analisada.

Quanto às variedades estudadas, verifica-se que as maiores injúrias observadas foram de $29,5 \%$, para a variedade SP89-1115 e de $72 \%$ para a variedade PO-8862 para o tratamento com saflufenacil + Assist, deixando claro que a existência de variabilidade genética entre as variedades de cana-de-açúcar influenciou os resultados.

Aos 7 DAA, constatou-se de uma forma geral reduções consideráveis dos sintomas iniciais de injúrias para algumas variedades e pequenos incrementos para outras, independente do tratamento químico testado. Ressalta-se que para o tratamento (ametryne + clomazone), os sintomas de injúrias foram incrementados em todas as variedades.

Maciel et al. (2008), estudando a eficiência dos herbicidas trifloxysulfuron-sodium + ametryne $\left(37+1.463 \mathrm{~g}\right.$ i. a. ha ${ }^{-1}$ e $0,2 \%$ de v/v de Aterbane) e hexazinone + diuron $\left(330+1.170 \mathrm{~g}\right.$ i. a. ha ${ }^{-1}$ e $0,2 \%$ de $\mathrm{v} / \mathrm{v}$ de Aterbane), verificaram que os herbicidas trifloxysulfuron-sodium + ametryne e hexazinone + diuron, aos 7 DAA promoveram níveis de injúrias acentuados na parte aérea das plantas de cana-deaçúcar. Os sintomas de clorose e bronzeamento seguidos de necrose das pontas e bordas das folhas foram constatados pelos autores como danos visuais provocados de forma mais intensa até 14 DAA.

Observa-se, aos 15 DAA, que a porcentagem de fitotoxicidade visual foi reduzida em todos os tratamentos em que se utilizou o herbicida saflufenacil em mistura e em algumas variedades com saflufenacil na maior dose aplicada isolada. As variedades tratadas com ametryne + clomazone continuaram a apresentar valores elevados de fitotoxicidade e apresentaram incrementos em relação a avaliação anterior, independente da cultivar analisada. Aos 21 DAA, verificou-se que os sintomas de injúrias foram reduzidos novamente em todas as variedades, independente do tratamento químico testado. Ressalta-se que o tratamento padrão (ametryne + clomazone) apresentou ainda as maiores injúrias visuais, com médias entre 11,75 e $20,75 \%$ de fitotoxicidade.

Aos 30 DAA, os sintomas de fitotoxicidade visual reduziram-se praticamente a metade em todos os tratamentos, independente das variedades analisadas, sendo que o tratamento (ametryne + clomazone) apresentava ainda as maiores injúrias para a maioria das variedades estudadas, variando entre 5,75 e 15,25\%. Aos 45 DAA observa-se que as injúrias reduziram de forma acentuada em todas as variedades estudadas, independente do tratamento químico analisado. Verificou-se, ainda, que as maiores injúrias, independente da variedade avaliada, foram proporcionadas pelo tratamento padrão (ametryne + clomazone).

Aos 60 DAA, verificou-se uma completa dissipação dos sintomas iniciais de injúrias promovidos pelos diferentes herbicidas em todas as variedades de cana-de-açúcar; dissipação esta atribuída à rápida emissão de folhas novas sem injúrias, o que determinou a redução das notas de fitotoxicidade atribuídas inicialmente.

A rápida recuperação das injúrias iniciais nas folhas de cana-de-açúcar provavelmente foi impulsionada e auxiliada pelas condições climáticas que sucederam à aplicação dos herbicidas, sendo principalmente devido à elevada temperatura e ao alto índice de precipitação pluviométrica, condições estas propícias para o rápido desenvolvimento da cultura.

AzANIA et al. (2006), avaliando a seletividade na aplicação de diuron + hexazinone $\left(1,170+330\right.$ g.i.a.ha $\left.{ }^{-1}\right)$, a hexazinone $\left(192,5+247,5\right.$ g. i.a. ha $\left.{ }^{-1}\right)$, metribuzin $\left(1,920\right.$ g. i. a. ha $\left.{ }^{-1}\right)$ e isoxaflutole $\left(127,5\right.$ g. i. a. ha $\left.{ }^{-1}\right)$, constataram que todos os herbicidas causaram sintomas de intoxicação às plantas de cana-de-açúcar até os 45 DAA e também observaram ausência dos sintomas aos 60 DAA. Em outro estudo de CHRISTOFFolETI et al. (2006), verificaram queo herbicida carfentrazon-ethyl, em todas as doses aplicadas, à semelhança do padrão metribuzin, foi seletivo à cultura da cana-de-açúcar, não tendo sido observada injúrias aos $45 \mathrm{DAA}$.

Verifica-se também que, independente do tratamento químico, as variedades mais sensíveis ou que apresentam maiores sintomas iniciais de fitotoxicidade quando da aplicação dos herbicidas testados foram: PO-8862, SP80-1842, SP80-1816 e SP83-2847, respectivamente.

Independente da variedade testada, o tratamento saflufenacil + Assist foi o que proporcionou as maiores injúrias nas diferentes variedades de cana-de-açúcar, seguido do tratamento saflufenacil + Break Thrue, por último, os tratamentos saflufenacil aplicado isolado e (ametryne + clomazone). 


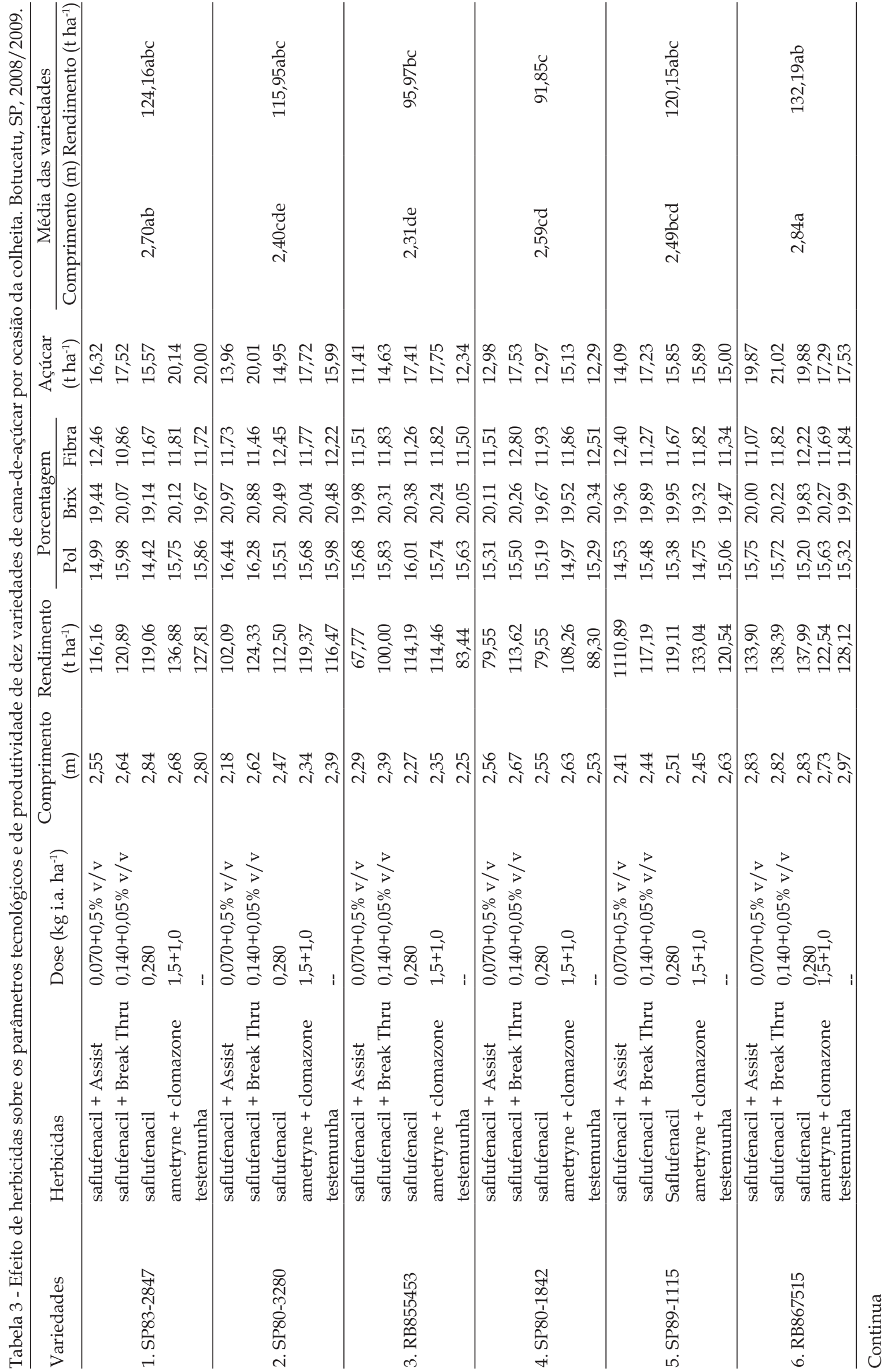




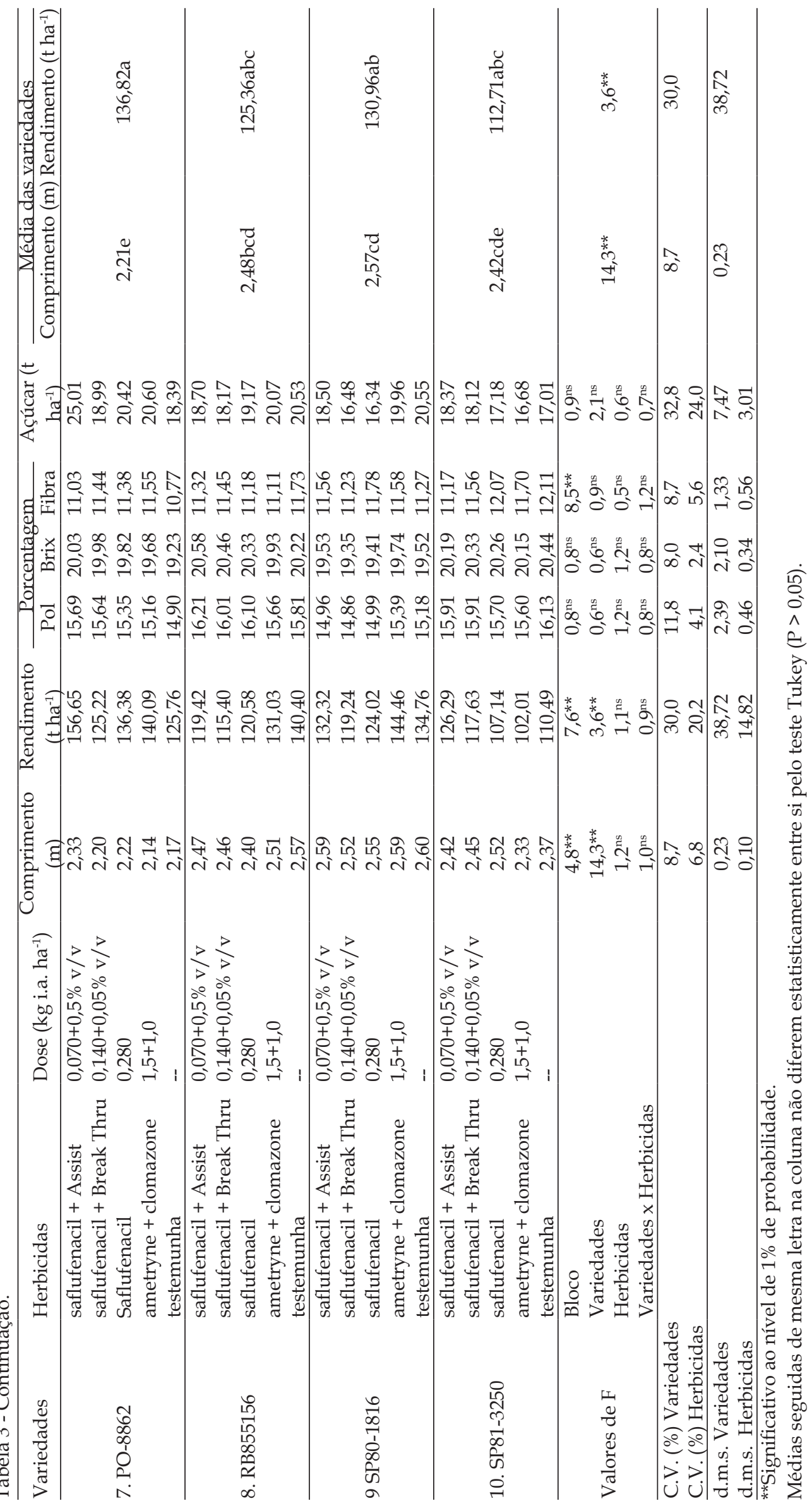


Os resultados dos parâmetros tecnológicos e produtivos: teores de pol, brix, fibra, quantidade de açúcar por hectare, comprimento e rendimento de colmos por área das variedades de cana-de-açúcar tratadas com diferentes herbicidas estão apresentados na Tabela 3. Nota-se que para estes parâmetros a interação Variedadex Herbicida não foi significativa, assim como também o fator Herbicida. Apenas houve efeito do fator Variedades para os dois parâmetros.

Observa-se que a variedade RB867515 foi a que apresentou o maior comprimento de colmos e o segundo maior rendimento destes dentreas variedades; contudo, a variedade PO-8862 apresentou o menor comprimento de colmos e obteve a maior média de rendimento de colmos por área.

Velini et al. (2000), avaliando a seletividade dos herbicidas oxyfluorfen e ametryne, aplicados em pré ou pós-emergência de dez variedades de canade-açúcar, inclusive a SP80-1842, observaram que o rendimento de colmos e teor de açúcar não foram afetados negativamente pelos herbicidas testados como ora verificado para a variedade dentro deste estudo.

Os resultados dos parâmetros tecnológicos: teores de pol, brix, fibra e a quantidade de açúcar obtida pelas variedades de cana-de-açúcar tratadas com diferentes herbicidas estão apresentados na Tabela 3. Verifica-se que não houve interação significativa entre Variedade $x$ Herbicida, bem como dos fatores principais: Variedadese Herbicidas. Assim, os efeitos observados nas variedades podem ser atribuídos às diferenças genotípicas e não a influência dos herbicidas testados.

Registra-se que a variedade PO-8862 foi o genótipo que proporcionou a maior produção de açúcar e a variedade SP80-1842 a que menos produziu.

Resultados semelhantes para as mesmas variedades foram encontrados por CARDOSO (2010), onde nenhum dos parâmetros tecnológicos analisados foi significativamente afetado pela ação dos herbicidas topramezone + Dash, topramezone + tebuthiuron + Dash e ametryne + tebuthiuron.

Os dados corroboram também aqueles de VICTÓRIA-FILHO; CAMARGo (1980) quando estudaram a tolerância da variedade de cana-de-açúcar CB41-14 a misturas herbicidas, pois verificaram que tanto a produção como as características tecnológicas da cana-de-açúcar não foram afetadas pela mistura herbicida hexazinone + diuron.

A variedadePO-8862, mesmo sendo inicialmente o genótipo que apresentou as maiores injúrias visuais causadas pelos diferentes tratamentos químicos, foi a que proporcionou a maior produtividade de colmos de cana-de-açúcar.

Nenhum dos tratamentos químicos testados afetou negativamente os componentes bromatológicos das dez variedades de cana-de-açúcar analisada.
Os rendimentos de colmo e açúcar não foram afetados por nenhum dos tratamentos químicos estudados para todas as dez variedades de canade-açúcar testadas.

Todos os herbicidas utilizados foram seletivos para as dez variedades de cana-de-açúcar em condição de cana soca.

\section{REFERÊNCIAS}

AZANIA, C. A. M.; ROLIM, J. C.; CASAGRANDE, A. A.; LAVORENTI, N. A. E AZANIA, A. A. P. M. Seletividade de herbicidas. III- Aplicação em pós-emergência inicial e tardia da cana-de-açúcar na época da estiagem. Planta Daninha, v.24, n.3, p.489-495, 2006.

CARDOSO, L.A. Seletividade do herbicida topramezone isolado e em mistura em variedades de cana-de-açúcar 2010. $58 \mathrm{f}$. Tese (Doutorado em Agricultura) - Universidade Estadual Paulista, Botucatu, 2010.

CHAPOLA, R.G.;HOFFMANN, H.P.; BASSINELLO, A.I.; FERNANDES-JUNIOR, A.R.; VIEIRA, M.A.S. Censo Varietal 2010 de Cana-de-Açúcar nos Estados de São Paulo e Mato Grosso do Sul. STAB: açúcar, alcool e sub-produtos, v.29, n.3, p.42-45, 2011.

CHRISTOFFOLETI, P.J.; BORGES, A.; NICOLAI, M.; CARVALHO, S.J.P.; LÓPEZ-OVEJERO, R.F.; MONQUERO, P.A. Carfentrazone-etil aplicado em pósemergência para o controle de Ipomea spp. e Commelina benghalensis na cultura da cana-de-açúcar. Planta Daninha, v.24, n.1, p.83-90, 2006.

CONSELHO DOS PRODUTOPRES DE CANA-DEAÇÚCAR E ALCÓOL DO ESTADO DE SÃO PAULO. Regulamento dos negócios de compra e venda de cana-deaçúcar no Estado de São Paulo. Manual de Instruções. 5.ed. Piracicaba: CONSECANA, 2006. 16p. 111p.

EMBRAPA (Brasil). Sistema Brasileiro de Classificacao de Solo. Rio de Janeiro: CNPS, 1999. 412p.

FAGLIARI, J.R.; OLIVEIRA JUNIOR, R.S.; CONSTANTIN, J. Métodos de avaliação da seletividade de herbicidas para a cultura da cana-de-açúcar. Acta Scientiarum, v.23, n.5, p.1229-1234, 2001.

MACIEL, C.D.G.; VELINI, E.D.; CONSTANTIN, J.; JARDIM, C. E.; BERNARDO, R.S., FONSECA, P. P. M., BARELA, J. D. e OLIVEIRA, J. S. Eficiência e seletividade dos herbicidas trifloxysulfuron-sodium + ametryne e hexazinone + diuron em função da tecnologia de aplicação e do manejo mecânico da palha de cana-de-açúcar na linha de plantio. Planta Daninha, v.3, p.665-676, 2008.

OSIPE, R.; TEIXEIRA, E.S.; OSIPE, J.B.; ERTHAL, K.T.; BELANI, R.B.; ETCHEVERY, M.I. Avaliação da eficiência do herbicida Kixor como desfolhante na pré-colheita da cultura do 
algodão. In: CONGRESSO BRASILEIRO DE ALGODÃO, 7., 2009, Foz do Iguaçu, PR. Resumos. Foz do Iguaçu, 2009.

ROLIM, J.C.; JANEGETZ, I.; GARMS, M.A. Tolerância de variedades de cana planta à herbicidas. 1 - cana planta, solo arenoso, em pré-emergência. In: CONGRESSO BRASILEIRO DA CIÊNCIA DAS PLANTAS DANINHAS, 22., 2000, Foz do Iguaçu. Anais. Foz do Iguaçu: SBCPD, 2000. p.294.

\section{SOCIEDADE BRASILEIRA DA CIÊNCIA DAS PLAN-}

TAS DANINHAS. Procedimentos para instalação, avaliação $e$ análise de experimentos com herbicidas. Londrina: SBCPD, 1995. 42p.

TERRA, M.A. Seletividade de diclosulam, trifloxysulfuron-sodium e ametryne a variedades de cana-de-açúcar. 2003. 60 f. Dissertação (mestrado em Agricultura) - Universidade Estadual Paulista, Botucatu, SP, 2003.
VELINI, E.D.; MARTINS, D.; MANOEL, L.A.; MATSUOKA, S.; TRAVAIN, J.C.; CARVALHO, J.C. Avaliação da seletividade da mistura de oxyfluorfen e ametryne, aplicada em pré ou pós-emergência, a dez variedades de cana-de-açúcar (cana-planta). Planta Daninha, v.18, n.1, p.123-134, 2000.

VICTÓRIA FILHO, R.; CAMARGO, P. N de Efeitos dos herbicidas nos teores de macronutrientes e nas características tecnológicas da cana-de-açúcar (Saccharum spp.) I - Misturas de herbicidas em pós-emergência. Planta Daninha, v.3 n.2, p.96-107, 1980.

VICTÓRIA FILHO, R.; CHRISTOFFOLETI, P.J. Manejo de plantas daninhas e produtividade de cana. Piracicaba: Visão Agrícola, USP/ESALQ, 2004. n. 1, p.32-37.

Recebido em 23/11/10

Aceito em 3/4/12 